\title{
DISCUSSION FOLLOWING THE PANEL ON FOREST PROTECTION
}

\section{A. W. Braine, Chairman}

.... Now gentlemen we have roughly half an hour for a discussion period which may take the form either of questions to individual members of the panel, or statements on fire protection or other forest protection problems.

\section{Major-General Howard Kennedy}

I would like a statement from Dr. Prebble regarding the effectiveness of the budworm spraying program in New Brunswick this past summer.

Dr. Prebble-Ottawa Valley

I think the answers will have to be brief. I can answer the question if we can have a brief statement of principles of just what is involved in the type of operation that is going on in New Brunswick at the present time. First of all I think it is necessary to state that advances in operational design in execution of the program in New Brunswick is a real milestone. Two years ago I don't think we could have found many people in Canada who would have been willing to admit that operational control over an area of $1,700,000$ acres, as was done this year, could possibly have been carried out. The problem is inherently a biological one, and solving the operation in detail is the first stage.

The second point I would like to make is that we have to get away from the concept of crop pest control when dealing with a forest crop. An annual crop turnover each year with virtual control of all the operations from sowing the seed to taking in the harvest gives a man operating that territory a pretty fair chance to see environmental results-in this case, the crop itself. Now the environmental circumstances are entirely different in a forest operation and consequently no measure of success dealing with circumstances in a given generation of the pests has necessarily any real significance in long term practice. Unless something that man does has an affect of long duraticn, it can be quite a fallacy to claim that any result has been obtained. From that point of view we don't as yet attribute any rank of success or failure to the workin New Brunswick. Operationally it is successful, but the long term affect will be measured in terms of how much change there has been in the population trend. In other words it must be done for several successive years, at least to the extent that trees are kept alive where otherwise they would be dead ...

That brings us into questions relating to the dynamics of insect population, and it is not wise to generalize from one problem to another. Some of these problems on restricted plantation areas, - the very intensively localized problems of the henlock looper-are compact problems which rise and fall in restricted areas and man has a pretty fair chance to do something about that. Bigger problems, such as the bud worm and tent caterpillar, but we will stick to the bud worm, are entirely different. First of all the outbreaks are much more prolonged. We have outbreaks of the spruce bud worm that are silil going on now in the 12 th and 13 th year and the areas standing year by year are still vigorous. 


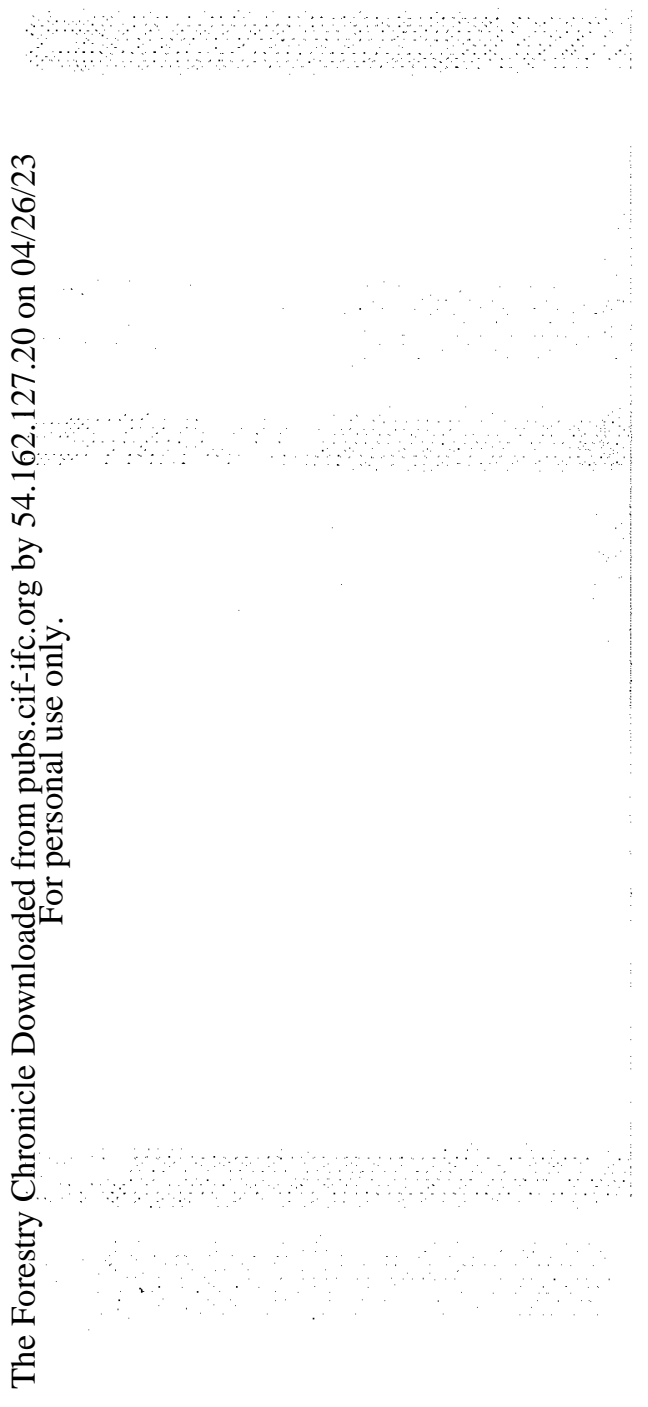

Second, the areas of infestation when discoverable, if you want to put it that way, are already huge. In other words we don't have thin points from these outbreaks. Some of the areas that were discovered fairly promptly still were within the 100 or even 1000 square miles and we often hear the question- "Why not count them at that year?"

There is a little fact here which I will try to explain briefly. It has its basis in the life history and the personal habits of that particular insect. One can see quite easily the circumstances in July, or early August for that matter, but between that time and the time in which action could be taken, next June at the earliest, there are two or three things going on which completely change the picture. First of all you have moths emerging in late July or early August and they themselves are dispersed by wind into various parts of the country. Dispersal is not measured in a matter of half miles or miles, it is more likely in terms of scores of miles, depending on the wind current. The second point that takes place is that after the eggs are laid there are two periods of dispersal, one in the late summer and the other in the spring. The one in the spring, dealing with very young larvae, can be exceedinly bothersome. So you can try to visualize the planning that could take place from July of one year until June of the next.- You are dealing with intangibles, and the areas of infestation-two or three of which I know quite well-have increased in ratio of one to 15 or 20 and no amount of survey work,-unless you can have a man on every acre, looking at every tree for egg plantation in the late summer and do the same just a few days before operations have to start the next spring,- and no amount of planning is going to change that fact.

In other words at the present time we will give full marks to those responsible for the operational details in New Brunswick in solving operational problem. In the second place, as I mentioned very briefly, we shall know practically nothing about the pathology at least in so far as it refers to the bud worm (for some years).

From the point of view of population dynamics, that is something that only time will tell, and it is extremely important in reaching an expression of opinion, not only in a short term, but in a long term trend coming from an operation of that kind to have some basis to put your feet. That raises the question of reserve areas whereby you can evaluate what is going on in sections of population undisturbed by spraying. If you have not that, you have no basis on which to reach an opinion as to what has happened.

I wish to mention another point that I referred to very briefly and then I will stop on this question. There is the question from the present to the future. Remember the question of composition of stand and so on. There are two or three instant exceptions to what is accepted as a general rule. That bud worm population is part of the aging process in the natural climax of the spruce balsam stand. We do have two or three instant exceptions in the various parts of Canada, including Newfoundland and Manitoba and some small segments in the Maritimes where populations have built up, but are very often sustained by drifting in from outside. 


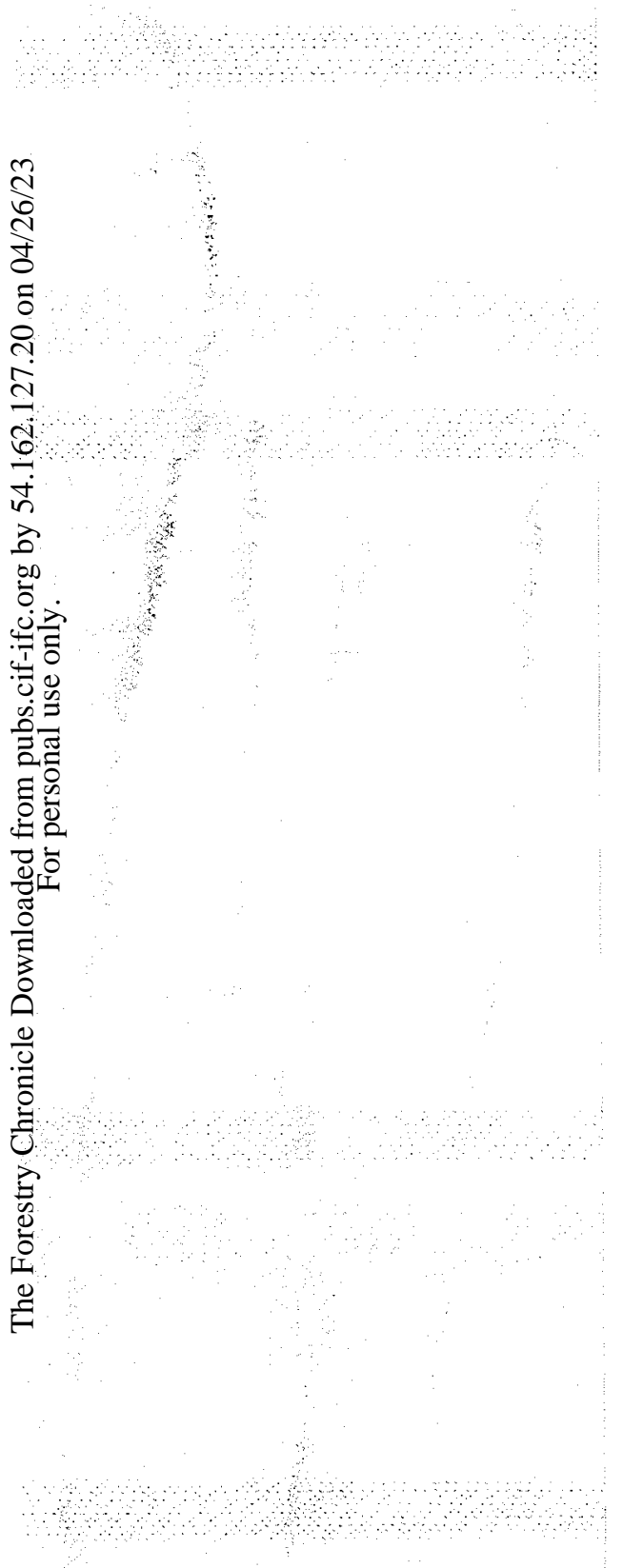

Apart from those instant exceptions, the bud worm problem is an unusual past of the fact that you have aging balsam stands which become extremely susceptible and they in turn favor the bud worm population in its survival at a time when they start producing year after year. I know that there has been a good deal of impatience to the reception of a suggestion that maybe control of this problem rests with man himself. I have heard of responses from the audience, "the same old guff" and that sore of thing, when this viewpoint is expressed and, therefore, am exposing myself to the same comments - the same old guff. But let us have it anyway. The same old guff is this, that we operate the woods - it is very hard to fly over a forest in North America where a man has not been. He has been there at one time or another and he is going to be there again, and if he is going to be there again perhaps he can be there more frequently and if he is there more frequently, he probably has a means of controlling this problem at its source, not at the tail end. We are still on an emergency basis in there and when spruce bud worm outbreaks develop over areas of tens of thousands, up to hundreds of thousands of miles, concurtently and when we are into emergency action-you have to admit that we are in emergency action because we don't want to keep on tree generation after tree generation. We recognize that we are behind the events. We certainly are behind the events in this operation in Eastern Canada now and that is fine. I am not suggesting that, therefore, the forest die. I am suggesting that we recognize that fact and if the program is put on the basis of saving stands that otherwise will die, but not based on the concept which would be very hard to maintain, that by our actions we are thereby stopping infestation, we will be on a much stronger basis and that is where I am going to stop at the moment. Thank you.

\section{G. F. Meyer-Ontario}

..... I do know that in our own organization, you can take it for what it is worth as compared to Quebec or any other province, where we have one provincial forest protection organization, we do feel that we have a definite advantage in such a situation as we found ourselves this summer. In the latter part of August and early September, the fairly high fire hazard concentrated in one district or two. We were able to draw men and equipment from other districts which were not so affected. We brought in 55 at least, experienced fire fighters and airoplane loads of equipment and so forth from other districts and supplemented the effort in the areas where these were required. In talking to some of the people who were concerned with the fire situation in the province of Quebec they seemed to think that this was a real advantage over a situation where there are a number of protective organizations more or less operating on their own. That is not my opinion particularly, it is some information that came to me from discussion of the subpect. I am merely stating our situation and you can draw your own conclusions. Thank you.

\section{J. Brule-Quebec Section}

I didn't catch exactly what Mr. Meyer wanted to know about Quebec ... whether or not the government conditions are more efficient than the 
other organizations on fire protection. It is a matter of climate, wind and perhaps intelligence of those in charge. I am talking about forest fire protection as carried on by the Southern St. Lawrence for this particular association in Quebec. We think that we have many active and efficient combination of efforts with the forest protection service of Quebec and as a matter of fact very little difficulty is encountered in each district where six different organizations are working jointly with the forest protection service of Quebec, on all the limits that are leased-besides the private lands, where efforts of the forest protection service are to be made ....

\section{J. O. Wilson-Quebec Section}

I would like to follow Mr. J. Brule in connection with the question that was raised about the forest protection in Quebec. There, of course, as you may all know we have what you might call a dual system. We have the Government system as outlined by Mr. Mackey of Ontario and Mr. Miller of New Brunswick but in addition to that we have the association system whereby we have about six large associations, perhaps seven or eight large associations where the companies predominate in the management of the affairs insofar as forest protection is concerned and the government of course has the overall supervision of what is going on. I would like to say that I think that is a step in the right direction, but we haven't gone far enough. I have listened with great interest to the various papers which told us what has been going on in the various provinces and my reaction to that is that I have heard it all before and I have heard it over and over again. And I think the next step is that we are just talking to ourselves. What we have to do is get out and get all that stuff outside, so that more people know about it and it is broadcast more than it is at the present time. We are concerned here, not only with what happened in the past, but what is going to happen in the future. I would say right now that our Government systems and the association systems are obsolete. They were set up 20 or 30 years ago when nobody went into the forest during the fire season, except the forest protection organizations whether government or private. Now we embark on an entirely different systen in our forests, with the result that we have men working in the forest almost throughout the whole fire season and the tendency is for them to go there and work more and more intensively. My vision of the future is that the prime responsibility for fire protection is going to be tied down onto the companies who are operating and they are going to impregnate their whole organization in a way that isn't begun to-day and we are going to have mass training of the men.

I hear, of course, and I see, and I have had experience with the training that we had for key personnel. But when a fire starts, the great trouble is there isn't anybody to deal with it who knows anything about the actual performance or what they should be doing in order to put the fire out. The key personnel are tied up doing something else. They have to look after the organization. They have to provide food for the men. They have to organize the transportation system. Well those of us who have had experi- 
ence logging, we know that that takes quite a lot of personnel. It takes very well trained men and so on, but when it comes to cutting the wood, we have to have a big army of men who actually do the wood cutting and it is the same way when they come to put the fire out, we have to have a big army of men who know what they have to do and get busy in doing it.

Somebody at the table there put his finger on it when they said that the tremendous cost of putting fires out is largely due to the fact that it takes us three or four days to get on with the job, instead of three or four hours. But of course we all know that if we are faced with a big conflagration the only thing we can do is get everybody down on their knees praying for rain ... and they actually do that.

We have to get ourselves organized in such a way that we can do something better than that. We have to get ourselves down in such a way that every man who is available anywhere near a fire at all gets on to the fire, and he knows what he has to do and gets busy and does it.

While I am on my feet I would like to revert to one of my hobbyhorses -this question of forest entomology. I an of course very much interested in what Dr. Prebble has said and I agree with most of what he said. But by and large I would say that we probably again got bogged down before we got to our objective. We get so far along the line and then we don't think about our objective at all. What they are doing in Northern New Brunswick, it leaves me cold and makes me tired. I would just as soon give a dead man medicine as do what they are doing down there. They would have been much further ahead if they had taken that area, put a few bull-dozers around it, made a broad enough strip and set fire to the whole lot. You would have got something then, but now you are not going to get anything but a lot of dead trees. 